\title{
Outcome-Based Regulatory Strategies for Promoting Greater Patient Safety
}

\begin{abstract}
Stephen D. Sugarman*
The patient safety movement seeks to reduce the number of avoidable injuries and diseases that patients suffer while in hospital. Two regulatory strategies in support of that movement are explored here. "Required disclosure" would rely on market responses to an increase in publicly available information about hospital errors. "Performancebased regulation" would require hospitals to reduce their error rate or suffer substantial financial penalties. Both approaches are designed to give medical service providers incentives to promote safety without resorting to "command and control" regulation under which government experts tell hospitals how to act.
\end{abstract}

\section{INTRODUCTION}

Hospitals are dangerous places. As discussed in Part I, in the United States a distressing number of patients suffer harm from preventable adverse events that occur while they are receiving treatment. Although many are concerned about this problem, and many strategies have been put forward for reducing sharply the number of adverse events that occur while people are in-patients, so far little headway is being made in making hospitals safer. Part I also explains why conventional medical malpractice law has not achieved and is unlikely to achieve the socially desired improvement in patient safety. Part II begins the exploration of the potential benefits of shifting the regulatory focus from behavioral "inputs" to health "outcomes." Part III analyzes a strategy termed "required disclosure" of each hospital's (preventable) adverse events. This strategy envisions greater competition among hospitals in terms of their safety records. Here existing disclosure regimes are described and the role of

* UC Berkeley Law School. 
third-party hospital-rating organizations is given special consideration. Using an expanded "informed consent" law to ensure the desired disclosure is also examined. Despite the theoretical attractiveness of a disclosure regime, Part IV describes potential shortcomings of such a scheme. Part V puts forward a more ambitious strategy termed "performance-based regulation" which would require hospitals not merely to disclose bad outcomes but actually to achieve ever-improved patient safety targets. Enforcement of these regulatory goals could be backed up with a potential range of sanctions and/or rewards. Although there are some important hurdles that would have to be overcome, this Article argues that "performance-based regulation" shows considerable promise in reducing the distressingly high morbidity and mortality rate now brought about through hospital errors.

\section{Setting Up the Problem}

Patient safety is a serious matter. ${ }^{1}$ When a patient goes into the hospital for treatment, it is generally understood that the medical problem cannot always be cured and that sometimes the treatment itself brings with it risks of unavoidable and possibly even fatal side-effects. But the patient does not expect avoidable bad things to happen to him or her because of unsafe conditions, actions, or omissions at the hospital.

Society traditionally has relied primarily upon the professionalism of physicians and other medical services personnel to ensure patient safety. This is backed up, to varying degrees in different legal systems, by medical malpractice law. Of late, however, newer strategies for promoting patient safety are being tried, have been put on the table, or could be put on the table. A spur to these new initiatives are depressing findings about patient safety (the phrase that will be used here, although this topic is in a narrower sense a matter of hospital safety). As discussed below, there is now a widespread belief that many errors (or mistakes) are made in the course of hospitalization that seriously harm or kill patients - errors that seemingly could and should be avoided. These are commonly termed "preventable adverse events."

Whether these adverse events are actually the result of either physician malpractice and/or other hospital employee negligence as a legal matter is often put aside. The point is that observers believe that avoiding these bad outcomes is often not only theoretically but realistically possible. Whether that is true - i.e., whether our healthcare delivery system is actually capable

1 For a comprehensive look at the problem, see RoBERT M. WACHTER, UNDERSTANDING Patient Safety (2012). 
of reducing the rate and/or extent of these adverse events - is another matter. But the patient safety movement (comprising many different initiatives seeking to reduce these errors, as discussed below) is premised on the belief that it is.

More than ten years ago the Institute of Medicine (IOM) concluded that in the United States up to as many as 100,000 patients die each year because of preventable adverse events that occur while they are in the hospital. ${ }^{2}$ This is a large number. By comparison, at present about 35,000 Americans die annually from motor vehicle accidents; about 11,000 are murdered by guns; and about 400,000 die from tobacco products. A more recent study of Medicare patients by the Inspector General of the Department of Health and Human Services suggests that little or no progress has been made in reducing this number of patient deaths and that perhaps the higher end of the IOM estimate is actually too low. ${ }^{3}$ For example, more narrowly focused research carried out after the IOM study suggests that 100,000 people have been dying in American hospitals each year from hospital-acquired infections alone - infections that are thought to be largely preventable. Indeed, recent estimates suggest 180,000 deaths a year from hospital errors. ${ }^{5}$ And, of course, besides deaths there are many more patients who suffer lesser harms because of preventable adverse events; perhaps as many as ten times as many people suffer serious injuries from adverse events as die from them. ${ }^{6}$ Although not all adverse events are preventable, the Inspector General's recent research found that physician reviewers believed that nearly half of the adverse events were clearly or likely preventable.?

What are the important sorts of preventable adverse events? ${ }^{8}$ Many of the IOM-identified errors that occur involve drugs — the wrong drugs are given,

2 Inst. of Med., To Err Is Human: Buildng a Safer Health System (2000).

3 E.g., Daniel R. Levinson, Office of Inspector Gen., Dep't of Health \& Human Serv., Adverse Events in Hospitals: National Incidence Among Medicare BeNEFICIARIES (2010).

4 Monina R. Klevens et al., Estimating Health Care-Associated Infections and Deaths in U.S. Hospitals, 2002, 122 Pub. Health Rep. 160 (2007).

5 Hospital SAFETy ScORE, http://www.hospitalsafetyscore.org/about-the-score (last visited Mar. 8, 2014).

6 Frederick S. Southwick, Losing My Leg to a Medical Error, N.Y. Times, Feb. 19, 2013, http://www.nytimes.com/2013/02/20/opinion/losing-my-leg-to-amedical-error.html.

7 Levinson, supra note 3. For the best source of U.S. information about patient safety, see Agency for Health Research \& Quality Within the Dep't of Health \& Human SERv. (AHRQ), http://www.ahrq.gov/ (last visited Feb. 2, 2014). See WACHTER, supra note 1. 
the wrong doses are given, or properly prescribed drugs are not given. ${ }^{9}$ Many of the errors, as noted above, involve patients getting avoidable infections that injure or kill them (either at the site of surgery or at the site of some insertion into the body, say, a catheter or drip line). Some involve mistakes that happen on the operating table (although adverse events related to surgery are probably less preventable on average than other adverse events), while others involve mistakes (sometimes failures to act) when patients present at the emergency room or when they are supposedly recovering from treatment in their hospital bed. Some patients fall down or out of bed and are injured or die as a result. A list of so-called "never" events has been created listing bad consequences that simply should never occur, but alas they sometimes do. ${ }^{10}$

The reliability of reports of adverse events, or preventable adverse events, is open to question. Much of the data comes from self-reporting, some of which is required (as will be discussed below). Often, earlier errors are only identified later when there is a so-called unnecessary readmission of a patient to the hospital (e.g., someone who was discharged less than thirty days earlier and probably should not have been). Certain actions taken on behalf of patients are usually pretty reliable indicators that errors had earlier been made requiring the new intervention. But many preventable adverse events will not fall into this category. In research studies, adverse events are generally identified when patient medical records are retrospectively reviewed, but this is both expensive and itself potentially unreliable as reviewers, with the benefit of hindsight, know the subsequent outcome that the treating personnel did not know at the time. While these concerns raise issues especially at the individual patient level, they by no means undercut the reality of the problem at the population level.

Nearly twenty-five years ago a Harvard study found that four percent of hospital patients suffered adverse events, of which one percent were victims of malpractice and three percent more suffered other accidental harms. ${ }^{11}$ Newer data put the numbers much higher. The Inspector General's recent study found that more than thirteen percent of discharged Medicare patients

9 Sarah Berdot et al., Drug Administration Errors in Hospital Inpatients: A Systematic Review, 8 PLOS ONE, June 2013, at 1.

10 Quasi-public-business partnerships including the Leapfrog Group and the National Quality Forum (Describe) have helped develop "safe practices" and the "never" events lists. For a description of "never-never" events and the Leapfrog Group's role in their development and the group's position on such events, see, for example, LeAPFroG GrP., FACTSHEET (2008), available at http:// www.leapfroggroup.org/media/file/Leapfrog-Never_Events_Fact_Sheet.pdf.

11 Harv. Med. Practices Stud. Grp., Patients, Doctors and Lawyers: Medical Injury, Malpractice Litigation, and Patient Compensation in New York (1990). 
suffered from an adverse event that resulted in serious consequences, and more than a quarter suffered at least temporary harm from an adverse event. ${ }^{12}$ Assuming that the Inspector General is correct that nearly half of these events were preventable, ${ }^{13}$ this means that about six percent of Medicare patients suffered badly from mistakes that should not have happened. ${ }^{14}$ This problem is hardly confined to the United States; research in England a few years ago found that ten percent of patients suffered damage while in hospital. ${ }^{15}$

Regardless of the precise numbers, assuming it is correct that we have unacceptably high levels of patient harms while in the hospital, this would appear to demonstrate that tort law currently fails to achieve what the idealistic law and economics model of liability incentives hopes to achieve; that is, injuries that would be efficient to avoid are occurring. Of course, even the most ardent supporters of the law and economics view do not claim that tort law perfectly deters what it theoretically should. Why might this be the case for patient injuries? Maybe the problem lies in the way in which tort law is currently applied to medical settings. If so, perhaps there are imperfections within tort law that could be addressed by tort reform.

For example, the standard of care applied to doctors could be less deferential to the profession, or cost-barriers that now make it impractical to bring a tort claim involving only smaller injuries could be lowered, or more healthcare workers could be encouraged to both publicly identify errors and testify against those who commit them. Moreover, reform might even include, at least in part, the undoing of some of the pro-defendant tort reform changes that have come about over the past few decades through the legislative efforts of doctors and hospitals; e.g., artificial restrictions on the common law of damages might be lifted. ${ }^{16}$ The idea here is that if we were more serious about using tort law to improve patient safety we could alter perhaps both the law on the books and the law in action in a socially productive way. Some observers of the way medical malpractice law now works suggest a dramatic change in how the system works, creating non-judicial arrangements that would simultaneously

12 Levinson, supra note 3.

13 See supra note 7 and accompanying text.

14 Since Medicare patients are generally either over age sixty-five or disabled before being treated, perhaps they are more vulnerable to adverse events than are patients on average.

15 Ali Baba-Akbari Sari et al., Extent, Nature and Consequences of Adverse Events: Results of a Retrospective Casenote Review in A Large NHS Hospital, 16 Quality \& SafeTy Health Care 434 (2007).

16 Tom Baker, The Medical Malpractice Myth (2005). 
compensate individual victims of medical error while seeking to promote greater patient safety. ${ }^{17}$

The focus of most of those in the patient safety movement, however, is quite different. It rests on the belief that tort law or its reform will never realistically give us the level of patient safety we want and ought to be able to attain. This lack of confidence in a better tort law being the solution could itself stem from many different possible conclusions. For example, some might conclude that even an ideal tort law would fail because, say, causal proof will frequently be impossible to gather that proves that the patient was the victim of an unreasonable risk, or that the way that malpractice insurance is priced will inevitably blunt the financial incentives of tort law. Others might argue that, as a political matter, it is currently implausible to expect to reform tort law in ways that might yield improved patient safety. Still others might say that practical problems in the way the system operates will always preclude making it wise to rely on tort law to yield the level of safety we believe can and should be achieved; e.g., it is simply too difficult under current rules for many victims to discover that their negative outcome should not have happened (a conclusion that may rest on the belief that when healtheare providers fear tort litigation they will not only fail to come forward to voluntarily disclose avoidable injuries, but may in some cases actually cover up errors). In any event, tort skeptics are looking to other strategies for improving patient safety.

Of course, one might favor a multipronged approach that meshes both an improved and more powerful tort law with other reforms as the best way forward in improving patient safety. This Article's focus is on the other reforms, however. Yet, it should be noted at the outset - a topic to which I will return at the end - that if a better regulatory strategy were available, its political acceptance might actually be more readily achieved if it were combined, at least in some respect, not with a strengthened tort law, but rather with a displacement of tort liability.

Those identified with the patient safety movement have focused on a wide range of strategies that they believe or at least hope will bring about positive change. Some emphasize requiring better training; others favor the development of more reliable "systems" to treat and care for patients, ${ }^{18}$ and for some that

17 E.g., Comm. on Rapid Advance Demonstration Projects: Health Care Fin. \& Delivery Sys., Liability: Patient-Centered and Safety-Focused, in NonJudicial Compensation, Fostering Rapid Advances in Health Care: Learning from System Demonstrations 81 (Janet M. Corrigan, Ann Greiner \& Shari M. Erickson eds., 2002).

18 E.g., Pascale Carayon et al., Human Factors Systems Approach to Healthcare Quality and Patient Safety, 45 Applied Ergonomics 14 (2014). 
includes embracing routine checklists for hospital procedures (modeled, for example, on airline safety systems) $;{ }^{19}$ others seek greater safety through improved information technology ${ }^{20}$ (so that, among other things, healthcare providers will have better data in front of them before they act); others favor linking the payment for services by insurers to healthcare providers on the performance of certain steps in the course of patient treatment (steps that are thought likely to reduce adverse events), and so on. The federal government's Agency for Healthcare Research and Quality (AHRQ) focuses, among other things, on research that can help sort out effective ways to reduce preventable adverse events, and, for example, it provides "Patient Safety Primers" on a whole range of better safety strategies. ${ }^{21}$ Note well that all of these approaches target specific activities for hospitals to engage in.

The focus of this Article is different. It examines two regulatory strategies that concentrate only on results - on outcomes - on how many (preventable) adverse events are attached to the targeted actor(s) and whether the rate is going down.

\section{Thinking Generally About Outcomes}

The two regulatory strategies I explore here that are aimed directly at outcomes I term "disclosure" and "performance-based regulation." Under the first approach, government requires ongoing disclosure of adverse events and/ or preventable adverse events and then leaves it to the market to use that information to improve safety. ${ }^{22}$ Under the second, the government assigns patient safety targets to the regulated parties and holds them accountable for achieving those targets (through sanctions and/or rewards).

The simple idea underlying both of these approaches is to create stronger incentives - primarily but not necessarily exclusively financial incentives -

19 Peter Pronovost \& Eric Vohr, Safe Patients, Smart Hospitals: How One Doctor's Checklist Can Help Us Change Health Care from the Inside Out (2011).

20 Comm. for Data Standards for Patient Safety, Bd. on Health Care Serv., Patient Safety: Achieving a New Standard of Care (Philip Aspden, Janet M. Corrigan, Julie Wolcott \& Shari M. Erickson eds., 2004).

21 Patient Safety Primers, Agency for HealthCare Research \& Quality, http:// www.psnet.ahrq.gov/primerHome.aspx (last visited Feb. 2, 2014).

22 For a wide-ranging examination of the role of disclosure in promoting a range of social goals including improved healthcare performance, see William Sage, Regulating Through Information: Disclosure Laws and American Health Care, 99 Colum. L. Rev. 1701 (1999). 
for safer outcomes. The view that required disclosure alone could stimulate stronger market pressures towards greater patient safety rests on twin beliefs: first, with better information about results inserted into the marketplace, safer providers will gain a larger share of the healthcare business, thereby subjecting patients to a lower risk of avoidable adverse events; and second, out of fear of losing patients to those safer providers the currently less-safe providers will improve their performance, which will also benefit patients. Performance-based regulation assumes that competition for business will itself not suffice to bring about the optimal level of patient safety and that healthcare providers must be directly prodded by government with penalties and/or rewards to achieve safer outcomes.

In thinking about both of these strategies, one must consider who should be the object of those incentives. The focus could be on hospitals, or on individual physicians, or on both hospitals and physicians. Since so many of the avoidable adverse events suffered by patients in hospitals are not the result of physician acts ${ }^{23}$ (or omissions readily attributable to physicians), this suggests that a hospital focus is needed, and that will be the emphasis here.

One potential U.S. concern about a hospital-only focus, however, is the traditional independent contractor relationship between hospitals and doctors who perform surgery on hospital patients (or provide other medical services to their patients while in the hospital). When this is legally acknowledged, it means that hospitals are not liable in tort for malpractice committed by the doctor, a result quite at odds, for example, with the clear liability of airlines for pilot error. ${ }^{24}$ In light of this legal independence (as well as long-standing social norms), hospitals have traditionally been thought to be shy about trying to exercise oversight over these "outside" doctors, apart from rare instances of outliers who are understood to have made so many mistakes as to actually lose their so-called "hospital privileges" to operate there.

This doctor autonomy (to the extent that it actually still exists) is clearly threatened if patient outcomes in hospitals are what must be disclosed or are the measures used in setting hospital safety targets. Indeed, I assume that advocates of both plans would want hospitals to pay serious attention to the performance of doctors who treat patients in their hospitals, regardless of whether the doctors remain formally independent contractors for torts and perhaps other purposes. This threat to physician autonomy is one reason why many doctors - even those with especially safe patient-outcome records instinctively might oppose these reforms..$^{25}$

\section{LeVINSON, supra note 3.}

24 Paul C. Weiler, Medical Malpractice on Trial (1991).

25 For valuable insights into this tension between doctors and institutions, see Robert 
Yet, this picture of the "independent contractor" doctor is perhaps out of date and may be quickly changing. First, many doctors have long been employed by the enterprise that owns the hospital in which they work. This is true for many Veterans' Administration doctors, university doctors, and county hospital doctors. Second, many hospitals recently have begun to purchase the practices of doctor groups whose patients are typically treated in the buyer's hospital(s), making those doctors employees of the larger organization. Third, many hospitals these days are employing "hospitalists." These are doctors who work in the hospital and are taking over care functions that formerly were provided by outside doctors. Fourth, in a variety of ways courts are holding hospitals liable for at least some behavior by doctors who might formally be considered independent contractors. Hence, in many respects, hospitals already have substantial responsibility for the doctors working on the premises ${ }^{26}$ The extent to which individual doctors in those situations are subject to controls, supervision, and reviews by other hospital staff members is left for hospitals to determine, taking into account potential costs as compared with potential benefits including possibly reduced medical malpractice liability.

One central feature of both the disclosure strategy and the performancebased regulatory strategy is their reliance on what are believed as reliable data in the measurement of outcomes. Key here are two interrelated points. First, we need to be reasonably confident that we are measuring the right things, and second, we need to be reasonably confident that we are accurately measuring them. ${ }^{27}$

M. Wachter \& Peter J. Pronovost, Balancing "No Blame" with Accountability in Patient Safety, 361 New Eng. J. Med. 1401 (2009).

26 For a call for healthcare group tort liability as a way to promote better patient safety, see William M. Sage, Medical Liability and Patient Safety, Health Afr., July 2003, at 26.

27 These points are well illustrated if we consider the seemingly wholly unrelated matter of the No Child Left Behind (NCLB) strategy for dealing with educational quality in America. See Why Won't Congress Reform the No Child Left Behind Act?, NAtion (Aug. 18, 2011), http://www.thenation.com/video/162851/whywont-congress-reform-no-child-left-behind-act. The congressional goal behind this bipartisan effort is to improve the educational attainment of American children across the board. Actually required, however, are higher test scores in English and math. Alas, those might not be the right/best outcomes to demand for a number of reasons. First, good test scores may not reflect real learning, and second, there is more to education than English and math. Indeed, two apparent results of NCLB have been a focus on "teaching to the test" and only in those tested subjects (to the abandonment of or reduction in attention to history, science, art, music, etc.). Third, the reliability of the test scores has also been 
One can imagine how these problems could plague schemes aimed at patient safety. First, if the regulatory goal is to reduce patient deaths, what if fewer people died from errors, but at a cost of fewer people being cured because socially desirable interventions were abandoned in the face of fears that they were more susceptible to error? Second, what if fewer people died from errors, but at a cost of some people being denied medical care or being denied care by the doctors and hospitals with the best records? Third, what if fewer lives were lost to error, but a much larger number of serious injuries were incurred instead? Fourth, what if a widespread cover-up of deaths from errors was engaged in up by those subject to the regulatory regimes so that the measured level of patient safety became quite unreliable?

A quick look at the world of in vitro fertilization (IVF) suggests some analogous concerns. People seeking babies via this method may well shop among doctors specializing in the technique in hopes of finding one who will treat them and give them the best chance of success. A natural question for would-be parents to ask, and one about which at least some doctors in this field are quick to offer data, is the doctor's past success rate. At first blush, this seems desirable because it would seem to give doctors an incentive to have a high success rate and would probably cause the more successful doctors to gain a large share of the market. But, even apart from any question about whether doctors are being truthful, if doctors believe that their future business depends on a high success rate, they might well decide to be quite selective in which patients they accept for IVF treatment. This could lead to the denial of service (or denial of access to especially talented doctors) to those most in need of special help (e.g., older women). To be sure, some doctors might decide to specialize in harder cases and justify their lower success rate by the nature of their practice. Yet many would-be clients might not appreciate this subtlety in the data, and they might also find it hard to distinguish those whose lower success rate is genuinely the result of taking on harder cases from those who are just not as good at the technique. Moreover, what about doctors seeking a mix of patients? People seeking IVF treatment might also not have a good sense of what outcomes to look for and act upon when presented with "success" data by doctors. Is it a successful fertilization on the first try or after many attempts? Is it a successful birth, a single birth without unwanted twins or triplets, a healthy child rather than one with "disabilities"? Of course, data could be provided on all of these dimensions, but too much information could overwhelm patients and undermine the value of what is being disclosed; and

questioned (cheating by teachers in various ways, having certain children stay home on testing days so as not be in the test pool, etc.). These on-the-ground realities reflect the concerns noted above. 
if left on their own, individual doctors might well cherry-pick and report the data that make them look best, leaving would-be patients having to decide between apples and oranges.

Yet, the inability to achieve the perfect should not become the enemy of the best. Data upon which to measure success need not be exactly what we want it to be for a regulatory intervention to be able at least to move society in the right direction (even if we do not get as far as we would like). ${ }^{28}$

\section{Required Disclosure as a Strategy to Improve Patient Safety}

As already briefly explained above, if government requires hospitals to disclose information about adverse events (and/or preventable adverse events), conceivably this could make for much greater competition among hospitals in terms of patient safety risks, leading to safer patient outcomes. This Part explores this regulatory option by first describing and discussing national disclosure obligations already in place, and then examines possible ways of strengthening those obligations at the federal and state level (including through tort law) as well as the roles that third-party certifying agencies now play and might even more powerfully play in auditing and reporting on patient safety outcomes.

\section{A. Existing National Disclosure Requirements}

To a modest degree, the U.S. government has moved in the required disclosure direction. Different branches of the federal government currently gather information about hospitals, for example by requiring hospitals to publicly report deaths and certain other bad outcomes. ${ }^{29}$ This data includes death rates from heart attacks, heart failure and pneumonia, as well as thirty-day readmission rates for such patients (which does not necessarily reflect error but could well reflect a mistaken early release). Through Medicare's Hospital Compare web-portal, it is already possible for consumers/patients to go online

28 After all, while the corporate disclosures required in a variety of circumstances by the securities laws do not perfectly achieve their goals, few would want to return to a regime in which disclosures were completely voluntary.

29 Data is collected and generated by the Agency for Healthcare Research and Quality (AHRQ), the Centers for Disease Control and Prevention (CDC), and the Centers for Medicare and Medicaid Services (CMS). 
and compare three hospitals in a specific geographic area on these and other dimensions. ${ }^{30}$

Hospitals are also supposed to report death rates from surgery to repair a weakness in the abdominal aorta, of those admitted for broken hips, and of those who suffer breathing failure. Presumably those data will also soon be available to view online. Data is also available, or in some cases will soon be available, concerning other serious complications including: collapsed lung due to medical treatment, serious blood clots after surgery, a wound that splits after abdominal or pelvis surgery, broken hips from falls after surgery, serious bedsores, bloodstream infections after surgery, and infections from large venous catheters. These are the "never-never" events which are all supposed to be avoidable. ${ }^{31}$ Data is further available on other hospital-acquired conditions such as objects left in the body after surgery, air bubbles in the bloodstream, mismatched blood types, infections from urinary catheters, falls, and signs of uncontrolled blood sugar. These also appear to be bad consequences that it is agreed should almost always be avoided. ${ }^{32}$

In addition to information about patient harms, the government also collects other data - on success rates for various treatments, patient satisfaction survey results, and more - and makes those data available as well. But no overall ranking of hospitals is attempted. Moreover, given the mixing of quite different sorts of information, it is not all that easy to get a sense of the comparative safety record of each hospital across the board. Put more charitably, although the government agency in charge is presumably trying to be helpful, while taking pains not to mislead, I found the official website not very user-friendly and I am not the only one. I say this because it turns out that other third parties are taking this public information, often combining it with other data, and making it available to the public in ways that may well strike consumers as rather more useful.

30 Hospital Compare, MedicARe, http://www.medicare.gov/hospitalcompare/search. html (last visited Feb. 3, 2014).

31 LEAPFrog GrP., supra note 10.

32 Although sometimes the government releases rather precise data for each hospital, because of reliability concerns and reporting limits at other times one gets only an indication of whether the hospital's results are better or worse or statistically no different from national averages. 


\section{B. Third-Party Disclosure Practices}

The Leapfrog Group is one body that tries to make patient safety shopping easier. ${ }^{33}$ First of all, it gives a single overall safety score to each hospital: A, B, $\mathrm{C}, \mathrm{D}, \mathrm{E}$ or $\mathrm{F}$. Then it arrays much of the government data already discussed in an easy-to-view format, showing which results contribute importantly to the Leapfrog hospital safety score. But, in addition, Leapfrog surveys hospitals about behaviors it believes hospitals should engage in that are promising ways of improving safety. Those survey results also contribute to the hospital's ranking, and viewers can easily see whether a hospital in question claims to have adopted such procedures. Notice, therefore, how Leapfrog combines a focus on actual outcomes with a focus on what are believed to be outcomeimproving procedures.

Consumer Reports (CR) too has entered this marketplace and has created overall "safety scores" for a large number of hospitals throughout the country (although a fair number is not yet rated). ${ }^{34} \mathrm{Using}$ its familiar one hundred point scale that it regularly uses for rating products as varied as autos, computers, and vacuum cleaners, CR takes into account the data reported to and by the federal government on avoiding infections, avoiding readmissions, communicating about new medications and discharge, appropriate use of chest and abdominal CT scanning, avoiding serious complications, and avoiding mortality. So, like Leapfrog, CR melds outcomes data with process data. In addition, CR has tried to statistically adjust the official numbers to take into account the type of patients a hospital serves. Interestingly enough, while the patient safety scores of the highest-rated hospitals are in the $70 \mathrm{~s}$, many world famous and regionally famous hospitals have scores in the $30 \mathrm{~s}$ and $40 \mathrm{~s}$ (or in some cases $50 \mathrm{~s})$.

Yet another third party to join this process is The Joint Commission, a longstanding nonprofit organization that accredits healthcare organizations. ${ }^{35}$ It awards its Gold Star rating to hospitals meeting certain criteria, including patient safety criteria. The Joint Commission uses its own inspectors and public information to decide whether the Gold Star rating should be awarded. Interestingly, and somewhat distressingly, many of the famous hospitals that have The Joint Commission Gold Star rating are scored relatively poorly by $\mathrm{CR}$; whereas quite a number of hospitals with relatively high CR scores are not Gold Star-rated.

33 LeAP FroG, http://www.leapfroggroup.org/ (last visited Feb. 3, 2014).

34 Consumer RePORTs, www.consumerreports.org (last visited Feb. 3, 2014).

35 Jornt Comm'N, http://www.jointcommission.org/ (last visited Feb. 3, 2014). 
As seen in recent works by Tim Lytton, ${ }^{36}$ professional third-party certification is used in many fields, some of which is reliable and some of which is not. As Lytton shows, there need not be a single third-party certifier operating in a single industry. Indeed, it would appear that one advantage of having more than one third-party certifier active in an industry is that competitors can police each other and expose unreliable ratings given out by competitors. On the other hand, having multiple certifiers also runs the risk that some of them will be too easy on those they certify and in effect mislead the users of their service.

With respect to patient safety, we are in the fairly early stages of this third-party evaluation process. Perhaps over time groups like Leapfrog, CR and The Joint Commission will each refine its criteria in ways satisfactory to each of them that brings about more consistent results. Or perhaps one or two of them (or perhaps new entrants) will come to be understood as most reliable - or, alas, positive certification will turn out not to actually well reflect patient safety risk.

\section{State Disclosure Regimes}

In addition to national disclosure requirements, about half of the U.S. states (with more to come) have adopted rules requiring hospitals to disclose certain hospital-acquired infections. ${ }^{37}$ These results are gathered by state agencies and made available to the public online (and to some extent that data is relied upon by the third-party certifiers described above). As recent work by David Hyman, Bernard Black and others shows, some state websites are far more helpful than others in terms of credibility, user friendliness, and usefulness of the information provided..$^{38}$ While the information provided in some states borders on useless, these findings also show that there is enough knowledge out there to allow states who wish to do so to make their reports credible, useful, and user-friendly. ${ }^{39}$

36 Timothy D. Lytton, Kosher: Private Regulation in the Age of Industrial Foon (2013); Timothy D. Lytton, Competitive Third-Party Regulation: How Private Certification Can Overcome Constraints That Frustrate Government Regulation, 15 Theoretical Inquiries L. 539 (2014).

37 Ava Amani et al., Public Reporting of Hospital Infection Rates: Ranking the States on Report and Website Content, Credibility, and Usability, 183 STuD. Health TeCh. \& Info. 87 (2013).

38 David A. Hyman \& Bernard Black, Public Reporting of Hospital Infection Rates: Not All Change Is Progress (Nw. Law \& Econ. Research Paper No. 12-21, 2013), available at $\mathrm{http} / / /$ papers.ssrn.com/sol3/papers.cfm?abstract_id=2219510.

39 For further evaluation of these reporting systems and their contribution to patient 
One general problem here is that thoughtful patients will probably want to know not only how well a hospital does in eliminating preventable adverse events, but also how well it does in achieving the positive goals the proposed patient treatment aspires to. Yet the success rate of any hospital might well not be the same along both of these dimensions. In turn, a certification process that tries to blend high treatment success rates with low adverse events rates might well rank hospitals differently from one that focuses exclusively on the latter.

\section{Some General Comments on Existing Disclosure Regimes}

In any event, the more general point is that once hospitals feel the need to be certified or rated as high-quality providers in terms of patient safety, that gives the certifiers clout, and so long as the certifiers are viewed by both hospitals and the general public as reliable and not a product of corruption, the involvement of a combination of government agencies and these nonprofit organizations could serve a valuable social purpose.

Looking at the data which is currently being collected and disclosed, notice that some of it is about adverse events more broadly (only some of which are preventable) and other of it seeks to be more narrowly focused on (mostly) preventable adverse events. In either case, however, the important thing is the hospital's relative score. Hospitals not only cannot prevent all patients from dying, but also they are very unlikely to be able actually to reduce to zero what are thought to be preventable adverse events. But if statistical adjustments are reliably made for the type of patient the hospital serves and the treatment provided, then one should be concerned about hospitals with substantially worse scores than others whether the focus is on an adverse event or a thought-to-be preventable adverse event. For example, a helpful comparison could be made whether the bad score is calculated in terms of deaths of those who present at the emergency room with heart failure or in terms of those who die from infections at the site of catheters.

Basing relative ratings on mortality data has a reliability advantage because it would seem difficult for hospitals to cover up whether someone has died in hospital or even has died within thirty days of release. At the same time, the richness of the data on bad outcomes that are not fatal suggests that, as Consumer Reports has decided to do, a hospital may be more appropriately scored on a range of outcomes including but not exclusively based on mortality.

safety, see Nat'l Quality Forum, The Power of Safety: State Reporting Provides Lessons in Reducng Harm, Improving CARE (2010), available at http://www. psnet.ahrq.gov/resource.aspx?resourceID $=18516$. 
The tradeoff here is the greater possibility of nondisclosure through coverups or gaming.

The third-party certifiers so far described should be distinguished from the third-party consumer review-driven services that currently exist. Online services like Angie's List, Vitals, Yelp, and Healthgrades provide individual doctor ratings based primarily on voluntary patient satisfaction reports/surveys the website obtains..$^{40}$ The reliability of these is quite uncertain, however. Many people instinctively may think that consumers are much better able to judge and rate things like restaurants than doctors. Still, this voluntary patient reporting strategy could perhaps provide rather good-quality ratings if enough people participate in the process. But so far people seem much more ready to post opinions of where they have eaten or the hotel in which they have stayed than of their doctors, so that many of these rating services have received rather few reports on many of the doctors they rate. Plus, while a doctor's promptness, willingness to take time with a patient, ability to explain things clearly and the like are things that matter to patients, they are not direct measures of how good a doctor is at diagnosing and treating health problems and how good a doctor is at avoiding making mistakes. Yet, many of the doctor-rating schemes emphasize these interaction-with-patients factors - in part, of course, because these are matters on which patients can form and reliably offer opinions.

In an effort to improve the frequency and quality of patient-provided information about adverse events, federal officials have recently proposed reaching out to patients who think they have suffered from a medical mistake or are concerned about patient safety to report their experience to the government. ${ }^{41}$ This data could be compared with the reports filed by healthcare providers, and might, if nothing else, promote fuller and more accurate provider disclosures.

It might be far more helpful were experts (e.g., other doctors or professional data gatherers) to reliably rate doctors and have their ratings made available to the public. Yet, so far there does not seem to be available a fine-grained expert-driven rating system for individual doctors. My main point here, however, is to distinguish the professionally-based third-party certifiers like Leapfrog and The Joint Commission from these other consumer information providers like Yelp and Angie's List, which are bottom-up user reports-based. $\mathrm{CR}$ falls somewhat in between since it has combined both patient review data

40 AngIE's List, www.angieslist.com/ (last visited Mar. 26, 2014); VitALS, www. vitals.com (last visited Mar. 26, 2014); YELP, www.yelp.com (last visited Mar. 26, 2014); Healthgrades, www.healthgrades.com (last visited Mar. 26, 2014).

41 Robert Pear, New System for Patients to Report Medical Mistakes, N.Y. Times, Sept. 23, 2012, at A20. 
with government data and professional evaluations to generate its detailed rating system.

\section{E. Increased Disclosure of Patient Safety Data via Tort Law?}

The discussion so far has assumed that if government were to act at all to require hospitals to disclose data about patient safety, it would do so through legislation or regulatory rules. But it should also be appreciated that conceivably disclosure could come about via the judiciary. What I have in mind here is disclosure required as part of tort law's "informed consent" doctrine.

As part of the movement to enable (or require) patients to take more control over their bodies and the treatment they receive (or do not pursue), American tort law has embraced an ever-widening view of "informed consent." ${ }^{\text {" } 2}$ At the outset, the focus was on the idea that doctors had a duty to inform patients about recognized side-effect risks of proposed treatment so that patients could decide for themselves whether the risk was worth taking, no longer leaving it up to the doctor to decide for them whether they should have the treatment. ${ }^{43}$ Over time, disclosure requirements have been expanded in most American jurisdictions to include requiring the doctor to provide information both about potential alternative treatments (beyond that which is proposed) and about the risks of failing to be treated. ${ }^{44}$ In effect, the doctor has been made a fiduciary with a duty to give patients the sort of information they reasonably might consider material to their decision about treatment.

A few commentators and a few cases have asked whether the disclosure required by tort law should also include information about the record of the specific doctor proposing to perform the treatment, as well as the record of the hospital where it would be performed. ${ }^{45}$ Surely it is easy to see why patients might wish to know not only about success rates but also about adverse event rates. To be clear, the idea, simply put, is that a doctor would be required to disclose not only her general credentials (e.g., where she trained and how long she has been in practice) but also her success and failure rate with respect to the specific treatment at issue. And so too the hospital. For example, the doctor might have to tell the patient, say, that she had done the proposed surgery ten times before with eight successes and two failures (explaining what the

42 Peter Schuck, Rethinking Informed Consent, 103 YALE L.J. 899 (1994).

43 Canterbury v. Spence, 464 F.2d 772 (D.C. Cir. 1972).

44 Matthies v. Mastromonaco, 160 N.J. 26, 733 A.2d 456 (1999).

45 Johnson v. Kokemoor, 199 Wis. 2d 615, 545 N.W.2d 495 (1996); Aaron D. Twersky \& Neil B. Cohen, Comparing Medical Providers: A First Look at the New Era of Medical Statistics, 58 BRoOK. L. Rev. 15 (1992). 
failures were in terms of both not achieving the treatment benefit and negative consequences that were suffered, both avoidable and perhaps not). That sort of disclosure could be helpful, but by itself might not be all that valuable in helping the patient to decide whether to use this doctor or someone else, assuming the patient has decided to go ahead with the treatment. What would be needed is comparative data on other doctors.

So, the doctor here might further be required to say, for example, that the average success rate is ninety percent or that the success rate for the top twentyfive percent of doctors is ninety-five percent; and also the doctor might have to disclose that the top twenty-five percent of doctors have done an average of one hundred of these treatments as compared with her ten, and so on.

Following in this same vein, the treating doctor could also be required to tell the patient about the patient safety record of the hospital in which the proposed treatment is to take place, as well as comparative data about other hospitals. If nothing else, a patient today could readily be told of the hospital's CR rating, its Leapfrog rating, and whether or not it has a Gold Star from The Joint Commission. Moreover, to the extent that hospital data are available that are particularly relevant to the specific treatment being proposed (e.g., hospital-acquired infections at the site of catheters if the treatment is likely to involve a catheter), that data too could be provided to the patient (along with comparative data about other hospitals).

Were the tort route pursued, then whether the information actually disclosed was thought to be reasonably sufficient would be judged in actual cases in which the suing patients would offer evidence that was not disclosed to them that they claim should have been. Assuming the evidence was admissible, American juries would then normally decide whether informed consent had actually been obtained. The central point is that if failure to offer this sort of provider-specific safety risk information could be introduced as evidence in an informed consent case, then there is good reason to think that doctors and hospitals would have a strong incentive to make this disclosure (or if they did not, then at least savvy patients might well shop elsewhere for another provider). Failure to disclose would lead, not to a statutory or regulatory penalty, but instead to potential liability under malpractice law.

One potential shortcoming of trying to use informed consent law to improve health outcomes is the "causation" requirement of tort claims under U.S. law. It would not be enough for a patient to show that he or she was not given information about hospital safety that reasonable patients would want to have. In addition, under U.S. law it would have to be demonstrated that had the information been given the patient would have sought treatment elsewhere (or, more typically, that a reasonable patient would have done so) and would 
have had a better result. ${ }^{46}$ For a number of reasons, this causation requirement might be very difficult for many patients to demonstrate.

\section{Qualms About Relying on the Disclosure of Hospital-Specific Patient Safety Data}

As explained above, underlying the required disclosure strategy is not merely the desire to allow patients to make informed choices, but also the desire to prompt providers through the competitive process to become safer places for patients. That is, if providers believe that public knowledge of bad consequences from past errors will lose them business, then they are likely to be eager to avoid that consequence, and that in turn should lead to fewer errors; and in the meantime, more business would flow to safer providers, to the benefit of patients.

Yet, there are reasons to fear that competition in terms of patient safety may not be as robust as the simple consumer choice model envisions. First, people who use emergency rooms for their routine treatment or who are taken to an emergency room in a real emergency often have no choice in these matters in terms of either which doctors or which hospitals serve them, and so it is not easy to see how their circumstances provide a direct market incentive for safer treatment. This is not to say that the doctors and other hospital personnel they see are indifferent to patient safety. Of course they care. The point rather is that disclosure of adverse event rates of emergency rooms and/or of hospitals generally seem unlikely to be translated into more careful "shopping" by these patients.

Second, what about other patients? In the United States these days many people select a primary care physician who they view as their regular doctor. In the idealized picture, if they need more specialized treatment they then select a specialist, and if they need care outside of a doctor's office - say in a hospital or special surgery center or the like - they decide where to have that treatment. But the reality is often quite different. First of all, in practice, selecting one's primary care physician can itself be fraught with uncertainty and frustration. Most people in the United States have health insurance that

46 Perhaps a proportional award could be made instead of requiring proof of "but for" causation. See Twersky \& Cohen, supra note 45. In Israel this causation requirement is absent because failure to obtain informed consent is viewed as an insult to the integrity or identity of the patient, and so there is a wrong regardless of what the patient would have decided had she or he been given the material information in advance. See CA 2781/93 Da'aka v. Carmel Hospital 53(4) PD 526 [1999] (Isr.). 
gives them some choice, but nevertheless typically not all doctors in their geographic area are available to them. Often, many are not on their insurance plan's approved list. This might be good if their health insurer only included on its approved list those doctors with stellar records in terms of patient safety. But that does not appear to be the case. Also, many doctors are not taking new patients. They have all the business they can handle, and so those with the best records may not be available to patients seeking to shop on this basis.

Even from a constrained list, however, one could imagine a better market than we have today in the selection of primary care doctors on the basis of quality. In practice, nowadays, people probably select on the basis of personal acquaintance, recommendations from friends, or geographic convenience. Recommendations from friends probably are based primarily upon the friend's own personal (or family) experience with the doctor(s) in question, which might not turn out to be a good reflection of the doctor's overall quality (and it is unrealistic to expect most people to ask dozens of friends for advice before making their own choice). Some people approach a group practice they have heard good things about and simply find themselves assigned to a member of the practice they know nothing about. (The latter is not necessarily a problem if the practice team carefully brings in only doctors with good records and weeds out those with bad records. How often this happens is not currently clear.)

If people readily had reliable data about doctor quality, then presumably many would act on that. This could generate more business for those making fewer serious errors and having higher success rates, giving most doctors an incentive to be in this favored category. Yet, as described above, we do not have reliable rankings of individual doctors in terms of adverse events suffered by their patients and/or success with the treatment undertaken. Moreover, it is not at all clear that this sort of individual doctor ranking is likely to materialize in the near future.

But how serious a problem is this in terms of the in-hospital patient safety problem which this Article addresses? That requires looking at the ways in which specialists and hospitals are selected. Do, or can, patients actually select hospitals on the basis of their ratings by Leapfrog, CR, The Joint Commission and so on? Often the answer will be "no." Many patients are linked to a single hospital by their health insurance plan, and for many others there is realistically only one local hospital that is physically available to them. Moreover, while some patients might shop for health insurance with an awareness of which hospital would be used, surely many will not. Many people will obtain health insurance through employment that might not give them any choice as to which health plan covers them, and even when there is a choice, hospital safety records may well not be high on the list of employee 
considerations when selecting a plan (as compared, say, with price or coverage terms), especially if they or a family member has not already used a hospital for a serious illness or injury that made patient safety issues salient to them. Again, notice here how health insurers could become important professional gatekeepers, but this does not appear to be a role they have been willing to undertake. ${ }^{47}$

Furthermore, many patients do not think of the treatment decision they are making in terms of the hospital where treatment will be provided. They are instead, at most, selecting the specialist who will treat them. And for that choice many people largely rely on (or must rely on) their primary care doctor for advice. Put differently, the selection of a specialist will typically include a selection of the hospital in which treatment will be carried out because that is where this specialist routinely works.

Some people's insurance does not require them to have a formal referral from a primary care doctor for them to be served by a particular specialist, but even so it would seem that those patients would typically ask their primary care doctor for advice anyway if they felt this were reliably offered. So, to what extent do primary care doctors base referrals on patient safety data? Based on informal conversations, I believe that at present they tend to refer to specialists based upon a combination of the past experience of their own patients (which might or might not reflect the specialist's overall performance), personal friendships, and the general reputation of the specialist (that the primary care doctor has a sense of based upon conversations with other doctors and the specialist's stature in the community based on institutional connection, paper presentations, and the like). If this is the way that referrals generally happen, it might at least help most patients avoid being sent to specialists with clearly bad records. ${ }^{48}$ But notice that the focus is on the specialist and not on the hospital where treatment will occur.

This raises the more general point that for hospitals, market pressures based on patient safety records may well be too indirect. As just noted, even where the patient in principle has a choice, it seems that ordinarily it is the specialist who chooses the hospital. To be sure, if specialists feared they would lose business if the hospital where they worked had a bad patient safety record, they might take their business elsewhere if they could. And, while some

47 Mark R. Chassin et al., Benefits and Hazards of Reporting Medical Outcomes Publicly, 334 New Eng. J. Med. 394 (1996).

48 Nonetheless, the National Practitioner Data Bank, which collects among other things negative data on malpractice claims against doctors and other professional sanctions, is not available to individual doctors to examine (except their own file) in considering to whom to refer a patient. 
doctors may have treatment privileges at a number of hospitals, this is by no means always the case. Hence, if pressed, many specialists might well have to up and move their entire practice elsewhere, which is a substantial inertia hurdle to overcome; for a surgeon this could well mean having to upend longstanding relationships with fellow treating professionals like nurses and anesthesiologists. Besides, doctors might conclude that change from within is more promising, exercising "voice" instead of "exit." And yet, in practice, they are probably going to have little control over how patients are actually treated outside of their operating room. Nonetheless, hospitals and individual doctors do care about their reputations and probably would want to have a strong positive reputation for safety regardless of whether that translates into more business. ${ }^{49}$

Third, a very different concern here is that while savvier people might use patient safety data to secure treatment by better doctors in safer hospitals, what about those patients who are not savvy or perhaps have hardly any choice? Perhaps they are low-income Medicaid patients in areas where most doctors and many hospitals just do not serve such patients, apart from emergency room treatment. Will they end up being served by more dangerous hospitals? Indeed, will more disclosure of patient safety data mean that the distribution of patient safety risk becomes even more related to a patient's socioeconomic status than it is today? $?^{50}$

Note, here, how this market for health services differs from product markets in which, for example, Toyota, if it makes a better vehicle, will probably do so for all of its line, or at least for all of the cars in any model it improves. Hence a modest number of would-be buyers can create positive externalities for many others. Yet if some health service providers are segmented to serve the poor, things are different. It is more like the problem of tenants who rent housing at all quality levels generally being unable to stimulate more caring slum lords. In addition, Toyota can reasonably quickly increase its market share, and Chrysler, if it makes a worse vehicle, can quickly lose much of its market share. Individual doctors, however, often cannot expand the provision of their services in the way product makers can expand their volume. Safer hospitals might be able to slowly expand their size, although probably without the flexibility of auto makers.

49 Edward L. Hannan et al., Improving the Outcomes of Coronary Artery Bypass Surgery in New York State, 271 J. Am. Med. Ass'N 761 (1994).

50 This is one of the fears that may similarly cause one to oppose using tort law's informed consent doctrine to force doctors to disclose their own past experience and patient outcomes. 
Beyond that, it has taken some time for the various auto rating and restaurant rating services to build up credibility with the consuming public. And, individual consumers typically feel capable of deciding whether their experience matches that of the various rating services available to them. Most patients are not going to have a great deal of experience with a range of providers of the same service and often will be incapable of deciding whether what they consider to be a bad outcome is the result of an error or an unavoidable risk. Hence, in practice, they or their referring doctor will have to rely on third parties whose reputation for reliable evaluations is only now being created.

\section{Performance-Based Regulation to Promote Patient Safety}

\section{A. Existing Financial Incentives}

Consider first the way medical care is traditionally paid for in the United States and the flow of funds that follows if an error occurs in the hospital. Sometimes, of course, the patient immediately dies. Often, fortunately, nothing bad actually happens or a small bad consequence is quickly remedied. But frequently, instead, what happens is that a great deal of additional medical intervention is called for. Sometimes the patient recovers; sometimes not. In any event, conventionally the relevant insurance provider will pay for the cost of that extra medical treatment - never making any attempt to determine whether the need for it was caused by an avoidable adverse event or simply the result of an unavoidable turn of events that put the patient in need of more care. The upshot, as a recent study revealed, is that hospitals often wind up financially profiting most from these hospital error cases.$^{51}$ Researchers are not suggesting that hospital staffs are deliberately causing the errors in order to profit from them, or that hospital administrators are uninterested in reducing errors because of negative financial consequences to the hospital that might result. Nonetheless, this payment arrangement would be viewed by many as bizarre, inappropriate, and, if nothing else, symbolically creating a perverse incentive that should not continue.

Aware of this situation, Medicare has begun taking steps to change the ground rules. One current strategy is to refuse to pay for the additional treatment made necessary because of errors (including readmissions that should have,

51 Sunil Eappen et al., Relationship Between Occurrence of Surgical Complications and Hospital Finances, 309 J. Am. MED. Ass'N 1599 (2013). 
instead, been handled by a longer initial stay with further treatment). ${ }^{52}$ The idea is that in such cases the hospital should take responsibility for the added costs, not the government insurer. This is not only thought fair, but such a policy now gives the hospital a financial reason to avoid these errors in the first place (since it will otherwise have to incur out-of-pocket costs for which it will not be reimbursed), ${ }^{53}$ although research questions whether there is a positive impact of such financial incentives on the rate of adverse events like catheter-associated infections. ${ }^{54}$

There is considerable appeal in this strategy although a couple of caveats are in order. One is the risk that if the hospital is faced with the prospect of no further reimbursement, it now has an incentive to skimp on extra needed services when they turn out to be needed after all. To be sure, too much skimping could mean the need for yet more services, but somewhere in there is the potential of worse care that saves the hospital money. This is perhaps most vividly seen if the patient dies quickly after the error occurs (and could have been saved with lots of costly intervention), although again it is not being claimed that providers are adopting a deliberate strategy to let patients die in response to the Medicare initiative. ${ }^{55} \mathrm{~A}$ different approach, designed simultaneously to lower costs, improve safety, and improve positive outcomes, is to award a lump sum to an appropriately designated team (or team leader) which oversees the patient's treatment, leaving it to the group to sort out what is the best way to achieve good results without errors at a reasonable cost. Various experiments are being carried out along these lines. ${ }^{56}$ At the same time, and cutting in the opposite direction, it remains to be seen whether having to provide further care without being reimbursed for it actually puts enough money on the table to stimulate hospitals to reduce their adverse event rates significantly. ${ }^{57}$

52 Robert M. Wachter, Nancy E. Foster \& R. Adams Dudley, Medicare's Decision to Withhold Payment for Hospital Errors: The Devil is in the Details, 34 JonN Comm'n J. Quality \& Patient Safety 116 (2008).

53 There are actually a variety of ways in which hospitals can be made to internalize these costs, which will not be explored here.

54 Grace M. Lee et al., Effect of Nonpayment for Preventable Infections in U.S. Hospitals, 367 New ENG. J. Med. 1428 (2012).

55 See also Somnath Mookherjee et al., Potential Unintended Consequences Due to Medicare's "No Pay for Errors Rule"? A Randomized Controlled Trial of an Educational Intervention with Internal Medicine Residents, 25 J. GEN. INTERNAL MED. 1097 (2010).

56 Ezekiel J. Emanuel, The Arkansas Innovation, N.Y. TIMEs, Sept. 6, 2012, http://opinionator.blogs.nytimes.com/2012/09/05/the-arkansas-innovation/.

57 One examination suggests that the financial penalty imposed by Medicare by 


\section{B. A Proposed New Approach}

A different idea in somewhat the same broad vein would call for the application of "performance-based regulation" to this problem. Indeed, the application of this regulatory strategy to the problem of patient safety was proposed in 2009 by Australian scholars Enrico Coiera and Jeffrey Braithwaite. ${ }^{58}$ Simply put, the relevant legislative body (let's say the U.S. Congress were the idea transposed to America) would adopt a regulatory target in terms of improved patient safety. For discussion, let us assume it is a reduction in deaths from preventable adverse events of five percent per year for five years (perhaps starting in year two or three after the law is adopted to give the target hospitals a chance to plan). If successful, this would mean a twenty-five percent reduction in avoidable patient deaths at the end of the first phase of the plan's operation. Of course, the plan could target more than a reduced number of deaths - say, also including serious injuries - using the same sort of target reductions.

It should be understood that under this approach, while the twenty-five percent figure is an industry target, each individual hospital would have its own target based on its past performance record. The hospital that currently has an average safety record would be given a five percent per year reduction target. Those that already have better than average safety records would have smaller reduction targets; those with worse records would have larger reduction targets. If this plan worked, then over time, not only would the overall error rate decline, but also the safety records of hospitals would become more similar.

As with performance-based regulation in general, hospitals would then be left on their own to figure out ways to achieve their regulatory targets. They could learn from each other as different strategies were tried and proved to be more or less effective. Rather than the government, they would decide what safety systems worked best, what new training helped them reach their targets, what extra information technology investments paid off, and so on. They could experiment in various ways as part of their internal adverse event-reduction initiative.

Those that achieved their targets could be praised by the government, and those that exceeded their targets could be praised even more (and possibly given financial awards for doing so, more on this below). Still, perhaps serious praise could be reserved for those who after achieving their targets were at least safer than average or perhaps even in the top quarter in terms

itself is insufficient. Peter D. McNair, Harold S. Luft \& Andrew B. Bindman, Medicare's Policy Not to Pay for Treating Hospital-Acquired Conditions: The Impact, 28 Health Aff. 1485 (2009).

58 Enrico Coiera \& Jeffrey Braithwaite, Market-Based Control Mechanisms for Patient Safety, 18 Quality \& Safety Health Care 99 (2009). 
of safety. The praise strategy can be seen as analogous to receiving a "safe provider" government certificate. And if that is all that were done, it would be a version of the required "disclosure" strategy already discussed above. But this ignores the question of how to deal with failures.

A number of possible strategies are available to deal with those who do not meet their targets. Simplest to understand, and harshest, those who fail to meet their target and continue to remain well below the average in terms of patient safety could be effectively put out of business by denying them some key accreditation or authorization they need to carry on (or, perhaps, by having government refuse to provide insurance coverage for services provided there). At the extreme, this threat could indeed be used, although of course the hope would be to never have to exercise the sanction. But this could be thought too draconian and disruptive - a penalty reserved perhaps for only the truly gravest failures. But about the rest who have some shortfalls against their targets?

One solution would be to impose financial penalties, based on broad estimates of the social costs (including harm to patients themselves) of the adverse events. This is perhaps broadly analogous to what a scheme of "strict liability in tort" for adverse events might look like (where a bad hospitalbased consequence would have to be demonstrated, but no proof of fault in the individual case would have to be shown). The key point here is that the financial penalties would be more than merely the cost of the extra medical treatment made necessary by the bad outcome. They would reflect additional harm to the patient. To be clear, the point of financial penalties is to create the right financial incentive to improve patient safety, not to collect the money. Hence, setting the penalties at the proper level is not an easy task. They need to be enough to stimulate desirable changes in the conduct of hospital personnel, but not more than that, since performance-based regulation is not designed to be either a money-raising scheme or a victim compensation scheme.

Significant failure by hospitals to achieve targets could also lead to intense administrative oversight. This is perhaps analogous to what the Department of Labor tried some years ago in enforcing the Occupational Safety and Health Act of 1970 (OSHA) ${ }^{59}$ Basically it told employers that if their worker health and safety record was good, they would never or almost never be inspected. But if their record was bad then a swarm of inspectors would descend on them and help/force them to make changes. This is also perhaps analogous to some ways that American school districts have tried to deal with failing

59 As personally related to the author by fellow Berkeley Professor Robert Reich, who served as Secretary of Labor at the time of this experiment. See 29 U.S.C. ch. $15 \S 651$ et seq. (2013). 
schools under their charge - either send in teams of support people to help the school to change and/or "reconstitute" the school by replacing its leader (the principal) and nominally firing the entire staff, leaving it to the new leader to decide which, if any, to rehire. At the most modest, the worst performers could simply be put on an "unsafe hospital" list provided to the public by the government and that too would, in effect, be one way of implementing a disclosure strategy of the sort discussed above.

A somewhat different approach to providing incentives to better hospital safety performance would be to use carrots instead of sticks, or perhaps a combination could be employed. For example, hospitals that achieved their goals could receive subsidies and those that exceeded their goals even larger subsidies, perhaps varied depending on whether the hospital was at that point above or below the national average in terms of safety. Or, performance-based targets could have two levels. Failure to reach the first level, say, a three and a half percent annual improvement, would result in penalties, and achieving beyond, say, a six percent improvement would lead to bonuses (paid for, to the extent available, by those on whom penalties are imposed).

Coiera and Braithwaite proposed including a "trade" feature in their performance-based regulation strategy, modeling their proposal on the "cap and trade" idea that has been used to regulate air pollution by some industries and a central focus of efforts to reduce carbon emissions in the fight against climate change. ${ }^{60}$ Simply put, hospitals doing better than their own targets could "sell" their excess safety improvements to other hospitals, and indeed hospitals that could not meet their own targets would have to purchase these excess credits from others to remain compliant with the program. This approach, at least in theory, would create incentives for the industry as a whole to reduce preventable adverse events in the most efficient way possible. One potential concern with the "trade" feature is that the safety gains might be disproportionately concentrated in certain hospitals (and of special concern would be a situation in which those were the hospitals that disproportionately served wealthier patients). Even if safety improvement were achieved in the most efficient way industry-wide, patients consigned to hospitals that don't improve but only buy excess safety credits from others are not likely to be pleased.

It is also important to understand that this sort of performance-based regulation is different from many "pay for performance" (P4P) strategies that have been tried out (and continue to be tried out) in the medical services field. Those other performance goals generally focus on inputs, not outcomes

60 Coiera \& Braithwaite, supra note 58. 
(although sometimes they are a mix) ${ }^{61}$ For example, a typical P4P plan might ask: when the patient presented in the emergency room with chest pain, was aspirin immediately given? And when leg surgery was called for, was there an appropriate black ink mark clearly placed on the proper leg? New York City's doctors who actually work for the city have recently negotiated a new compensation package that includes variable compensation awards that turn on how well the doctor conforms to these sorts of performance measures. ${ }^{62}$ Again, while experts clearly believe there is a strong association between these sorts of behaviors and better outcomes, the penalties/rewards do not turn on actual outcomes. ${ }^{63}$ In the sort of performance-based scheme Coiera and Braithwaite proposed and which I am imagining here, they would.

Absent adjustments for patient characteristics, these outcome measures raise the concern that hospitals will be compared in ways that do not fairly reflect who they are treating. For example, if only deaths are counted, hospitals treating far more frail patients might have many more deaths from the same errors than a hospital has that is treating far healthier patients with the same diseases. Also, the nature of the interventions that hospitals offer/provide might contain quite different risks of error (and also quite different benefits if successful). Further investigation is required to determine whether hospitals have sufficient variation on these lines to warrant such adjustments (and the practical feasibility of making them reasonably accurately).

Notice as well that, while performance-based regulatory targets might be aimed at preventable adverse events as Coiera and Braithwaite proposed, they could instead be applied to all adverse events. It would probably be easier and cheaper to reliably determine the latter. With appropriate adjustments in setting targets based on patient characteristics (itself an admittedly somewhat difficult task), a focus on all adverse events leaves the hospital itself in the strongest position to use its own expertise to sort out which are actually most readily and sensibly prevented.

61 For the American Medical Association's take on P4P, see PrInCIPLES for PAYfor-Performance and Guidelines for Pay-for-Performance Are the Official Policy of Our AMA, http://www.ama-assn.org/resources/doc/PolicyFinder/ policyfiles/HnE/H-450.947.HTM (last visited Mar. 25, 2014).

62 Anemona Hartocollis, New York City Ties Doctors' Income to Quality of Care, N.Y. Times, Jan. 11, 2013, at A1.

63 For a proposed "accountability" regime from the leadership of The Joint Commission that rests on evidence-based measures that have been shown to yield better safety, see Mark R. Chassin et al., Accountability Measures - Using Measurement to Promote Quality Improvement, 363 New ENG. J. MED. 683 (2010). 
Another concern, of course, is whether introducing a regulatory mechanism in which bad outcomes risk not only disclosure and a possible bad reputation but also steep financial penalties could lead to underreporting and misreporting in which errors are no longer properly disclosed, and worse, efforts are deliberately made to disguise the truth. The prospect of the latter might be largely precluded were hospitals required, as proposed by Coiera and Braithwaite, to have what are in effect "patient safety auditors." To be sure, we know that the world of Certified Public Accountants has in some cases failed the public, but overall it has probably done a great deal of public good, and over time we are learning more about how to keep the auditors from becoming pawns of the firms they audit (like separating their consulting businesses from their auditing roles and requiring the regulated firms to change auditors with some regularity). Furthermore, note that a system of performance-based regulation need not depend on a hundred percent of events reporting system; instead, a sophisticated sampling scheme using several types of measures might be both more manageable and more reliable in capturing a hospital's relative safety standing. ${ }^{64}$

Overall, it appears to me that directing actual regulatory muscle towards hospitals holds more promise of improving patient safety than does relying only on disclosure and the market. Performance-based regulation could deliver serious financial incentives that take into account the actual harms that hospital errors cause and not just the additional medical care that they might cause. After all, if a hospital error promptly kills a patient, the harm is great and there may be no additional medical expenses that Medicare refuses to pay for (and even if Medicare refused to pay for the erroneous treatment, that could be a trifling penalty as compared with the loss).

A delicate and related matter is that it will probably cost money to improve patient safety, and one must think about who should pay for that. Of course, I am assuming that patients will benefit enormously. Does this simply mean that the costs of better safety should be passed on in the price of healthcare? Perhaps, but note too that an additional benefit of safer healthcare practice will be less need to provide the patients who benefit with the costly healthcare that previously was needed to deal with the aftermath of the mistakes. As already discussed, we seem to be in somewhat of a transition in terms of who bears those costs. That will have to be taken into account, therefore, in deciding how the expenses of safer care are to be allocated.

Determining just how much of a reduction in adverse events to require in a performance-based plan is also a difficult question. To demand too little is

64 For a thorough appraisal of existing and potential reporting options, see WACHTER, supra note 1. 
to tolerate more patient harm than is necessary. To demand too much, or too much too quickly, is, in effect, to impose a tax on healtheare, and raising the cost in this way would be very unpopular. This is why I have recommended something of an experimental first phase approach in which significant but not overwhelming safety reduction targets be phased-in a year at a time reaching, in the example so far given, twenty-five percent after five years of operation. At that point an evaluation can be made of what additional reductions seem appropriate to demand. After all, the goal here is not to impose fines on failure but to stimulate safer practices that lead to success. It would hardly be helpful if, in the end, many hospitals (especially those that disproportionately serve low-income patients) were primarily to be fined, leaving them with even fewer resources with which to serve their patients. On the other hand, it is equally wrong to give such hospitals a pass and thereby to tolerate their having significantly higher rates of avoidable adverse events. Setting the right target presents a challenge to steer us between these two unsavory outcomes.

In England, there has been some experimentation along the lines proposed here. Targets were set for clostridium difficile infection rates, with penalties threatened for failure to meet the targets. In the end, penalties were not imposed, but it appears that benchmarking and the threat of sanctions were sufficient to drive down the infection rate by forty percent. ${ }^{65} \mathrm{Of}$ additional interest, it seems that the reduction in adverse events was not achieved in the way that people had expected - a large investment in hygiene; instead the health gains were primarily achieved from more appropriate antibiotic use. This experience shows the advantage of leaving it to the regulated hospitals to decide how to solve the problem as compared with government telling them how to do it.

For performance-based regulation to even begin to be politically plausible in the United States, however, people would have to be convinced that what counts in terms of penalties (and/or bonuses) is sensible, reasonably accurately measured, and not readily gamed. Moreover, political acceptability might go up sharply if there were some tradeoff regarding tort law as part of the deal. For example, perhaps hospitals with especially strong and improving year-after-year results in terms of patient safety could be exempt from tort liability so long as they remain in the top group in terms of patient safety, or perhaps so long as they have safety records as good as or better than those in the very top group at the time the regulation kicks in. Note well how this

65 Alan Maynard, Pay for Performance: Proceed with Care!, in AccountabiLITY and Responsibility in Heatth Care 657, 672 (Bruce Rosen, Avi Israeli \& Stephen Shortell eds., 2012). 
bargain would provide a way for hospitals to pay for safety improvements through savings in medical malpractice insurance.

The bottom line for me is that as groups with reputations for integrity (like Consumer Reports and the Leapfrog group) are creating hospital safety rankings and making them public, we should feel comfortable that we are at least starting to gather enough of the reliable sort of information upon which a sensible performance-based regulation scheme could be built.

\section{Conclusion}

Those concerned about patient safety should be pleased that scholars and medical experts are carrying out studies and developing proposals that can help hospitals become less dangerous places for patients. Those efforts might well prompt hospitals to make changes for the better. But this is very different from arguing that regulators should require some, many, or all of these expert recommendations. To do so is to engage in traditional command and control regulation.

By contrast, this Article has explored two very different regulatory strategies that might prompt hospitals to select from among proposed practices the ones that they find do actually make a difference in bringing down their institution's rate of errors. These two regulatory strategies are both outcome-oriented. The simpler one is simply to insist that hospitals disclose results that are relevant to patient safety, counting largely on the market to pick up on these results to bring about financial pressure on hospitals to do better. While this approach holds some promise, various concerns were raised about why merely disclosing results may not suffice to achieve the desired safety improvement.

A more ambitious but potentially more effective regulatory strategy would be to require that hospitals not only disclose their patient safety results but actually improve them (of suffer government-imposed financial penalties). This approach, termed here "performance-based regulation," is broadly modeled on the "cap and trade" strategy being applied to concerns about global warming. If adopted, it could help stimulate a sharp reduction in error rates and unnecessary patient deaths.

For either of these two outcome-oriented regulatory strategies to function effectively, we must be confident that the regulated parties are gathering and fully disclosing the right information. Recent developments suggest that, even if we are not quite there yet, we are decidedly moving in the right direction in developing the reliable information-gathering and disclosure mechanisms that would underlie these reforms. 
